Available online at GSC Online Press Directory

GSC Biological and Pharmaceutical Sciences

e-ISSN: 2581-3250, CODEN (USA): GBPSC2

Journal homepage: https://www.gsconlinepress.com/journals/gscbps

(RESEARCH ARTICLE)

\title{
Bio-production of ethanol and biomass from wood particles and sawdust using conventional yeast
}

\author{
Ike Christian Chukwuemeka ${ }^{1,}{ }^{*}$, Onwuakor Chijioke Ethel ${ }^{2}$, Akwari Dike Kalu ${ }^{1}$ and Ogwuegbu Happiness \\ Odinakachi 3 \\ ${ }^{1}$ Department of Biological Sciences (Microbiology Programme), College of Basic and Applied Sciences, Rhema University, \\ Nigeria, P.M.B. 7021 Aba, Abia State. \\ 2 Department of Microbiology, Michael Okpara University of Agriculture, Umudike, P.M.B. 7267, Umuahia , Abia State, \\ Nigeria.. \\ ${ }^{3}$ Department of Microbiology, Abia State University Uturu, P.M.B. 2000 Uturu, Abia State. Nigeria.
}

Publication history: Received on 23 February 2020; revised on 31 March 2020; accepted on 02 April 2020

Article DOI: https://doi.org/10.30574/gscbps.2020.11.1.0048

\begin{abstract}
The enzymatic hydrolysis of wood particles and sawdust (waste) and fermentation of resultant sugar to produce bioethanol is both economical and efficient. Sawdust and wood particles contains high amount of cellulose which needs to be broken down to simple sugar (glucose) and fermented to produce ethanol. Trichoderma viride with high enzymatic (cellulase) activity was used to hydrolyse the processed wood particles and sawdust for 5 to 7 days after which the presence of reducing sugar was determined using Fehling's and Anthrone method. The determined sugar (\%) of $6.87 \pm 0.25$ was optimized to $23.90 \pm 0.18$ by adding commercial sugar. After optimization, the hydrolysate was inoculated with Saccharomyces cerevisiae isolated from palm wine and left to ferment for 7 days. During the fermentation, changes in physicochemical properties such as temperature, $\mathrm{pH}$, titratable acidity, sugar content, specific gravity, biomass and ethanol yield were monitored. The temperature fluctuated between $29^{\circ} \mathrm{C}$ and $30^{\circ} \mathrm{C}$ with pH decreasing from 5.8 to 4.1 , generating a biomass yield of $1.98 \pm 0.21 \mathrm{~g} / \mathrm{L}$. The sugar content (\%) reduced from $23.90 \pm 0.18$ to $3.83 \pm 0.32$ and $10.16 \pm 0.12$ ethanol (\%) was obtained at the end of the fermentation. Therefore, it is clearly evident that wood particles and sawdust are potential substrates for the production of ethanol, and extending fermentation days could lead to a higher ethanol yield.
\end{abstract}

Keywords: Ethanol; Biomass; Wood Particles; Sawdust; Palm Wine

\section{Introduction}

With the industrialization revolution, petroleum demand also increased [1]. The emission of gas as a result of combustion of fossil fuel over the last decades led to the desire and need for an alternative fuel. Petroleum and diesel are considered non-renewable resources and will be scarce in near future. Also, combustion of petroleum-based fuels increases net emission of carbon dioxide, different toxic and volatile compounds that are responsible for health hazards and pollutions such as benzene toluene and xylenes [2]. In recent times, there has been great concern in the production of substitute energy sources [3]. This led to the increasing demand for ethanol. Bioethanol was being widely recognized as a promising renewable and environment friendly source of energy. Generally, biofuel offer many benefits that include sustainability, reduction of greenhouse gas emissions, engine compression ratio and also reduce the environmental pollution [4]. Meeting the demands of bioethanol depends upon a regular supply of its primary raw material, i.e. biomass. Biomass has been considered as a major source of energy and it provides 10-14\% of energy. A major component of naturally-occurring biomass is cellulose [5].

\footnotetext{
*Corresponding author: Ike Chukwuemeka Christian Email: chrismacaug@yahoo.com
} 
Ethanol is an organic compound with a general name "alcohols". The use of ethanol by humans dates back to prehistoric times when it was largely consumed as a beverage. The benefits of ethanol include solvent, germicide, antifreeze, fuel and versatile intermediate for other organic chemicals. For these enormous advantages of ethanol, researchers have been geared towards the production of ethanol from various raw materials (or feedstock) and this lead to researches on production of ethanol from cellulose. Cellulose is a complex carbohydrate and a linear polysaccharide polymer with glucose monosaccharide units (300 to over 10,000 units with the formula $\mathrm{C}_{6} \mathrm{H}_{10} \mathrm{O}_{5}$ ). Cellulose is the most common organic compound on earth. Cellulose sources include plant fibers (cotton ( $90 \%$ cellulose), hemp, flax, and jute, corn, and wood (about $42 \%$ cellulose). Cellulose is useful in the production of paper and paper products, cotton, linen, and rayon for cloths, nitrocellulose for explosives, cellulose acetate for films, etc. It is also used as feedstock in the production of cellulosic ethanol [2].

Ethanol production utilizes two (2) categories of substrate which include crops and grain like corn, wheat, sugarcane, soybeans etc, and waste biomass such as straw corn and waste wood which is inexpensive. Production of ethanol from renewable sources of lignocellulosic biomass can decrease urban air pollution and reduce accumulation of carbon dioxide in the atmosphere [6]. The largest biomass energy source to date is wood, e.g forest residues (such as dead trees), yard chippings, woodchips and even municipal solid waste. Fermentation of sugars derived from inexpensive wood sawdust to produce bioethanol is economical and efficient. The sawdust containing cellulose is the most abundant form of organic carbon synthesized by plants. Cellulosic materials are renewable natural biological resources that can be used for the production of biofuels [7]. Various industries utilize huge volumes of cellulosic waste which provide a low-cost and sustainable resource for production of ethanol [8].

Bioethanol production through microbial fermentation provides an economically competitive source of energy [9;10]. Microorganisms are required to produce ethanol from lignocellulosic hydrolysates with high yield using an economically feasible process. Different fermentation organisms among bacteria and fungi have been reviewed with emphasis on their performance over lignocellulosic hydrolysates $[11 ; 12]$. Yeast cells are attractive for cellulosic ethanol process because they have been used in biotechnology for hundreds of years, and are tolerant to high ethanol and inhibitor concentrations. Therefore, this research was aimed at converting wood particles and sawdust (waste) into useful products (biomass and ethanol) using Trichoderma viride and palm wine yeast.

\section{Material and methods}

\subsection{Collection of materials}

The sawdust and wood particles used were obtained from carpenter line, timber in Umuahia and the palm wine was obtained from a palm wine seller at Umuariaga village in Ikwuano L.G.A. of Abia state. The Trichoderma viride was obtained from Federal Institute of Industrial Research, Oshodi, Lagos State.

\subsection{Sample and media preparation}

The fresh palm wine was aseptically collected into a previously sterilized bottle and taken to the laboratory immediately for analysis. The sawdust and wood particles was processed mechanically to reduce the length of fibre. The media used in the analysis was Sabouraud Dextrose Agar (SDA) which was prepared according to manufacturer's instruction. The prepared medium was well-mixed, heated to dissolve in a water bath and sterilized by autoclaving at $121^{\circ} \mathrm{C}$ for 15 minutes. After cooling to about $45{ }^{\circ} \mathrm{C}$ in a water bath, the media was poured into a sterile petridish and allowed to cool and solidify at room temperature.

\subsection{Enzymatic hydrolysis}

TheTrichoderma viride used for the hydrolysis was obtained as stock from already identified culture. A loopful of the organism was aseptically inoculated into 100 milliliters of sterile peptone water and allowed to grow for 2 to 5 days at room temperature. The processed wood dust was mixed with water in the ratio of $1: 4(\mathrm{w} / \mathrm{v})$. The mixture was sterilized (to eliminate microorganisms) by autoclaving at $121^{\circ} \mathrm{C}$ for 15 minutes. After cooling to room temperature, the mixture was inoculated with prepared Trichoderma viride inoculum and allowed to hydrolyse at room temperature for 5-7 days. From the third day of hydrolysis, it was tested for the presence of sugar using Fehling's qualitative method. The sugar content was determined at the end of the hydrolysis by Anthrone colorimetric method [13].

\subsection{Determination of specific gravity}


The pycnometer (specific gravity bottle) method used was described by [13]. The bottle was weighed when it was empty, clean and dry with its stopper in place and the weight was recorded (Wa). It was filled with freshly distilled water up to the capillary of the stopper. The outside was dried with an absorbent tissue and weighed and its weight was recorded $(\mathrm{Ww})$. The water was decanted and the bottle was dried without heating. This was done by rinsing with ethanol followed by acetone and lastly with diethyl ether. It was waved in the air for total drying. The dried bottle was then filled with the sample, it was weighed and the weight was recorded (Ws). The specific gravity was calculated as stated below:

$$
\text { S.G. }\left(\mathrm{g} / \mathrm{cm}^{3}\right)=\frac{W s-W a}{W w-W a}
$$

\subsection{Determination of sugar}

The reducing sugar was determined using the Anthrone spectrophotometric method of [13]. 1 milliliter of the sample (hydrolysate) was dispensed into a test tube and 6 milliliters of Anthrone reagent was added to it. The tube was corked and the content boiled in a water bath for 10 minutes. A reagent blank and a standard sugar solution was treated the same way. After boiling, the content of the tubes were diluted separately to 100 milliliters in a volumetric flask and their absorbances were measured in a spectrophotometer at $620 \mathrm{~nm}$ wavelength. The reagent blank was used to set the spectrophotometer at zero. Sugar (\%) was calculated as shown below:

$\begin{array}{lll}\% \text { Sugar } & & \frac{100}{\mathrm{~V}} \times \frac{\mathrm{AU}}{\mathrm{AS}} \times \mathrm{C} \times \mathrm{D} \\ \mathrm{V} & = & \text { volume of sample } \\ \mathrm{AU} & = & \text { absorbance of sample } \\ \mathrm{AS} & = & \text { absorbance of standard } \\ \mathrm{C} & = & \text { concentration of standard } \\ \mathrm{D} & = & \text { Dilution factor }\end{array}$

\subsection{Determination titrable acidity}

The titrable acidity was determined using the alkaline titration meter $[13 ; 14] .5$ milliliters of the hydrolysate was dispensed into a conical flask and 45 milliliters of distilled water was added to it and mixed well. 3 drops of phenolphthalein was added as an indicator. This was well mixed and titrated against dilute alkaline solution $(0.1 \mathrm{~N}$ $\mathrm{NaOH})$. The titratable acidity was calculated as stated below:

$$
\begin{array}{rlrl}
\% \text { TTA } & =\frac{100}{\mathrm{~V}} \times \mathrm{N} \times \text { Titre } \\
\mathrm{V} & = & \text { volume of sample titrated } \\
\mathrm{N} & = & \text { Normality of the titrant. }
\end{array}
$$

\subsection{Glucose optimization}

The sugar level of the hydrolysate was optimized with $170 \mathrm{~g}$ of sugar before inoculating it with palm wine yeast.

\subsection{Isolation of palm wine yeast}

The yeast was isolated from the palm wine using the direct culture method [16]. The palm wine sample was diluted by mixing 1 milliliter portion with 9 milliliters of distilled water in a test tube. Then, 1 milliliter of the diluted sample was further diluted aseptically by mixing in 9 milliliters of distilled water in a separate test tube. This gave a second dilution $\left(10^{-2}\right)$ which was used for inoculation. 1 milliliter of the diluted sample was inoculated into sterile petri dish, molten agar poured and mixed well. The inoculated plate was incubated at 28-30 ${ }^{\circ} \mathrm{C}$ for 2 to 5 days and observed daily for growth. When growth was established, the culture plate was examined closely for presence of distinct colonies. Inocula were aseptically collected and sub-cultured on sterile SDA plate and incubated at 28-30 ${ }^{\circ}$ C. Colony growth on the subculture plate was examined for discrete characteristics and pure culture was used for fermentation.

\subsection{Fermentation}

Two (2) loopful of the pure culture was aseptically dispensed into 100 milliliters of sterile peptone water and incubated at room temperature for 48 hours to serve as stock inoculum for fermentation. This was poured into the hydrolysate and incubated at room temperature for 7 days. During the period of fermentation, measurement of parameters such as $\mathrm{pH}$ change, temperature, sugar uptake, ethanol yield and biomass formation was monitored and recorded. 


\subsection{Determination of $\mathrm{pH}$}

The $\mathrm{pH}$ was determined using the Hanna electrode $\mathrm{pH}$ meter method [14]. The $\mathrm{pH}$ meter was switched on and allowed to equilibrate for 10 minutes. It was calibrated with buffered solutions of $\mathrm{pH} 4,7$ and 11 separately. The electrode of the $\mathrm{pH}$ meter was immersed into a 10 milliliters portion of the sample in a beaker. The $\mathrm{pH}$ value was read directly from the screen of the meter.

\subsection{Distillation and determination of quantity of ethanol}

The method of [15] was used. The fermented broth was dispensed into a round-bottom flask fixed to a distillation column enclosed in running tap water. A conical flask was fixed to the other end of the distillation column to collect the distillate. A heating mantle with the temperature adjusted to $78^{\circ} \mathrm{C}$ was used to heat the round-bottom flask containing the fermented broth. The distillate collected was measured using a measuring cylinder, and expressed as the quantity of ethanol produced in $\mathrm{g} / \mathrm{L}$ by multiplying the volume of distillate collected at $78{ }^{\circ} \mathrm{C}$ by the density of ethanol $(0.8033$ $\mathrm{g} / \mathrm{mL})$.

\subsection{Determination of biomass}

The direct weight measurement method of [17] was used. 100 milliliters of the fermenting substrate was measured into a light plastic centrifuge tube and spun at $1000 \mathrm{xg}$ for 5 minutes (the cells were separated by centrifugation). The supernatant was discarded and the cells in the centrifuge tube were carefully scraped out into a weighed pan, and 5 milliliters of water was used to rinse out the tube into the pan. The pan with its cell content was dried in the oven at 100 ${ }^{\circ} \mathrm{C}$ for 30 minutes. It was cooled in a desiccator and re-weighed. The weight of the cell plate was obtained by the difference and the formula below was used.

$\begin{array}{lll}\text { Biomass }(\mathrm{g} / \mathrm{L}) & = & \frac{1000}{\mathrm{~V}} \times\left(\mathrm{W}_{2}-\mathrm{W}_{1}\right) \\ \mathrm{V} & = & \text { volume of sample analyzed } \\ \mathrm{W}_{1}= & \text { weight of empty pan } \\ \mathrm{W}_{2}= & \text { weight of pan and dry cell paste }\end{array}$

\subsection{Statistical Analyses}

All obtained data from the different analyses were subjected to statistical analysis of variance (ANOVA) and descriptive statistics in form of mean and standard deviation and duncan post hoc were also used to assess the data and determine the level of differences between various samples and treatments using SPSS version 20.

\section{Results}

The results of quality tests on the Trichoderma hydrolyzed wood particles and sawdust liquor prior to fermentation with palm wine yeast are shown in Table 1 . The $\mathrm{pH}$ of the hydrolysate rose from $5.9 \pm 0.22$ (before optimization) to $6.20 \pm 0.15$ (after optimization). The specific gravity $\left(\mathrm{g} / \mathrm{cm}^{3}\right)$ increased from $1.01 \pm 0.31$ to $1.114 \pm 0.26$ before and after optimization respectively. The titratable acidity (\%) decreased from $0.48 \pm 0.09$ to $0.18 \pm 0.14$ while sugar content (\%) increased from $6.87 \pm 0.25$ to $23.90 \pm 0.18$ before and after optimization respectively. All values obtained were statistically significant when compared $(\mathrm{p}<0.05)$.

Table 1 Quality tests on the Trichoderma hydrolyzed wood-sawdust liquor before and after optimization

\begin{tabular}{lllll}
\hline Before optimization & $1.01 \pm 0.31^{\mathrm{a}}$ & $5.90 \pm 0.22^{\mathrm{a}}$ & $0.48 \pm 0.09^{\mathrm{a}}$ & $6.87 \pm 0.25^{\mathrm{a}}$ \\
After optimization & $1.114 \pm 0.26^{\mathrm{b}}$ & $6.20 \pm 0.15^{\mathrm{b}}$ & $0.18 \pm 0.14^{\mathrm{b}}$ & $23.90 \pm 0.18^{\mathrm{b}}$ \\
\hline
\end{tabular}

The physicochemical variations of wood particles and sawdust hydrolysate fermented with palm wine yeast are shown in Figures 1-7. The pH reduced from $6.20 \pm 0.15$ to $4.1 \pm 0.31$ after seven days of fermentation while temperature $\left({ }^{\circ} \mathrm{C}\right)$ fluctuated between $29 \pm 0.23$ and $30 \pm 0.11$ during the fermentation days. The titratable acidity (\%) increased from $0.18 \pm 0.14$ to $1.27 \pm 0.09$ while sugar content $(\%)$ decreased from $23.90 \pm 0.18$ to $3.83 \pm 0.32$. The specific gravity $\left(\mathrm{g} / \mathrm{cm}^{3}\right)$ decreased from $1.114 \pm 0.26$ to $1.00 \pm 0.15$, while biomass $((\mathrm{g} / \mathrm{L})$ increased from $0.14 \pm 0.06$ to $1.98 \pm 0.21$ during fermentation. Alcohol content (\%) increased from $1.22 \pm 0.03$ to a maximum of $10.16 \pm 0.12(\mathrm{v} / \mathrm{v})$ at the end of the fermentation. All values obtained during fermentation when compared were statistically significant $(\mathrm{p}<0.05)$ except for temperature $(p>0.05)$. 
Ike et al. / GSC Biological and Pharmaceutical Sciences, 2020, 11(01), 069-077

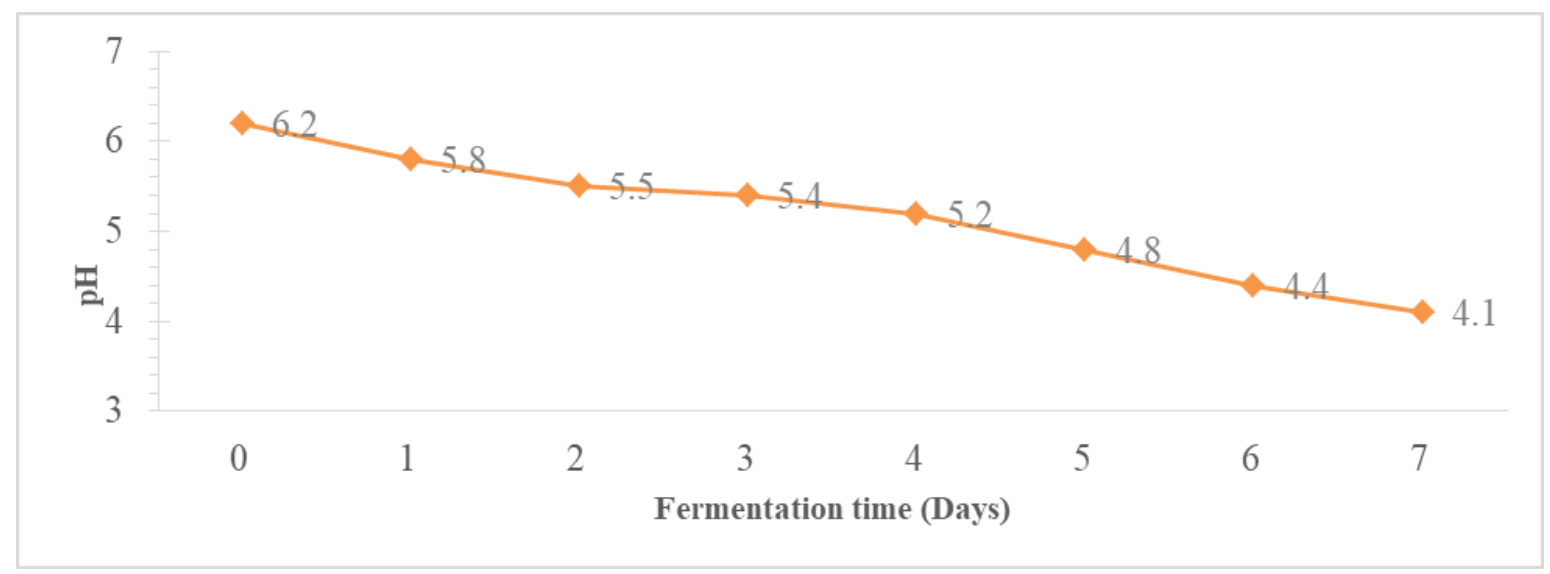

Figure $1 \mathrm{pH}$ variations during fermentation of the hydrolysate by Saccharomyces cerevisiae

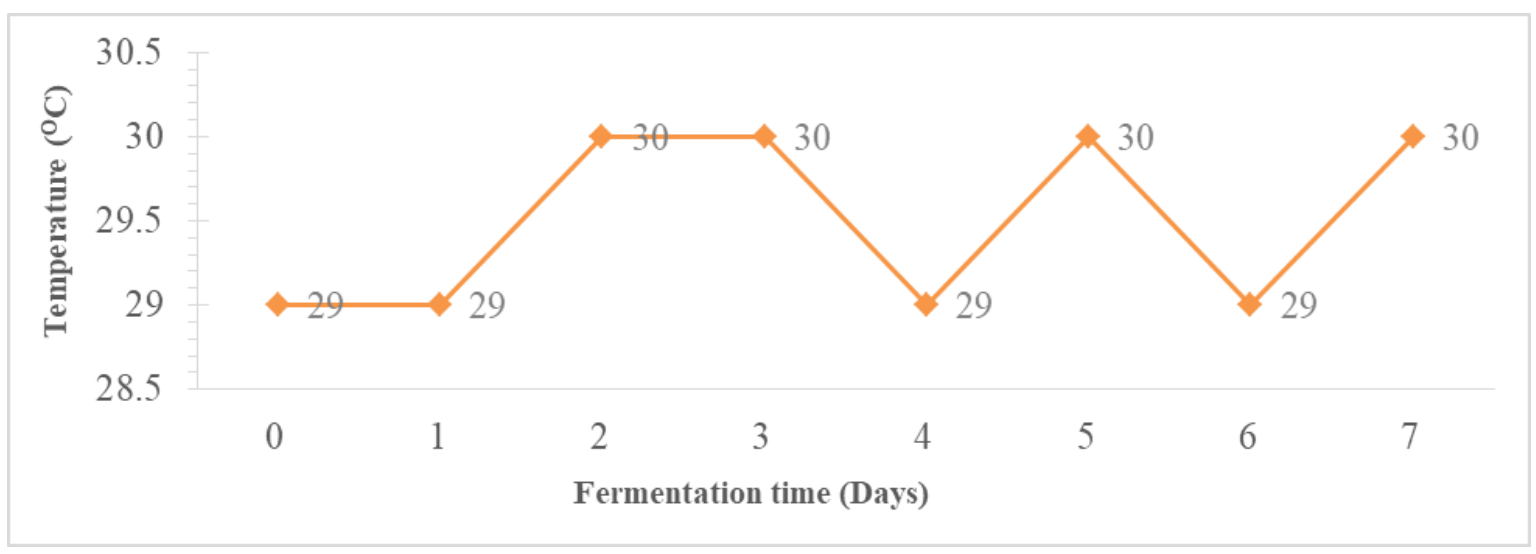

Figure 2 Changes in temperature during fermentation of the hydrolysate with Saccharomyces cerevisiae

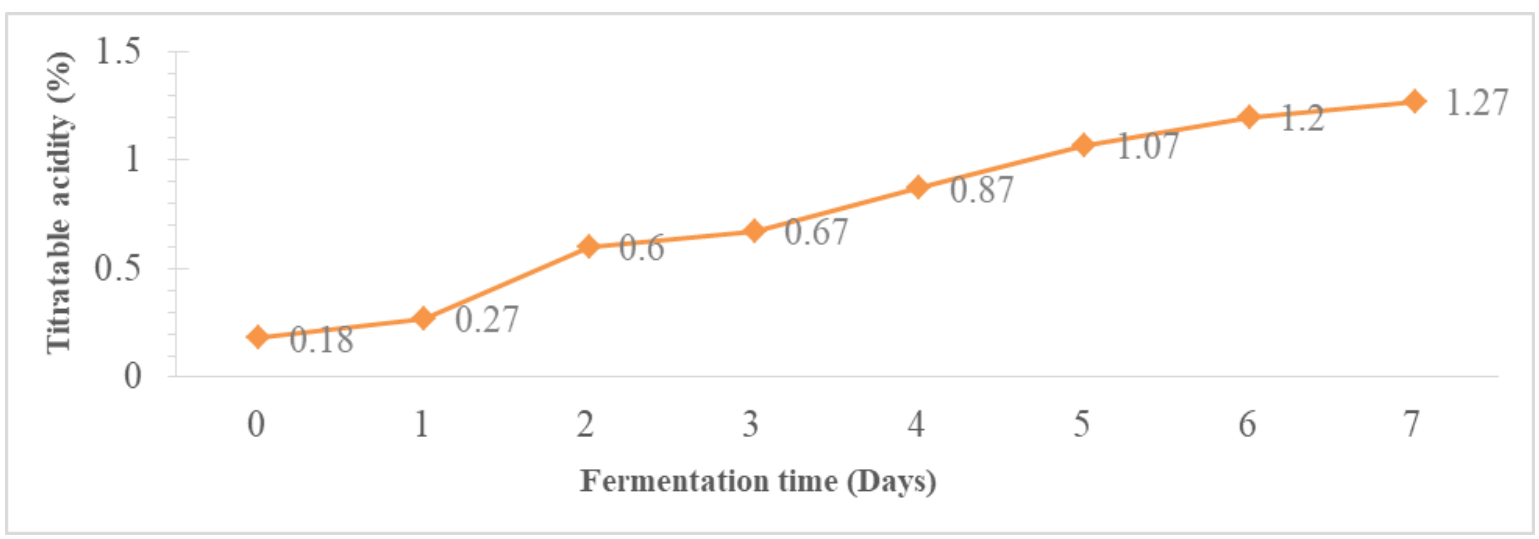

Figure 3 Changes in percentage titratable acidity during fermentation of hydrolysate with Saccharomyces cerevisiae 
Ike et al. / GSC Biological and Pharmaceutical Sciences, 2020, 11(01), 069-077

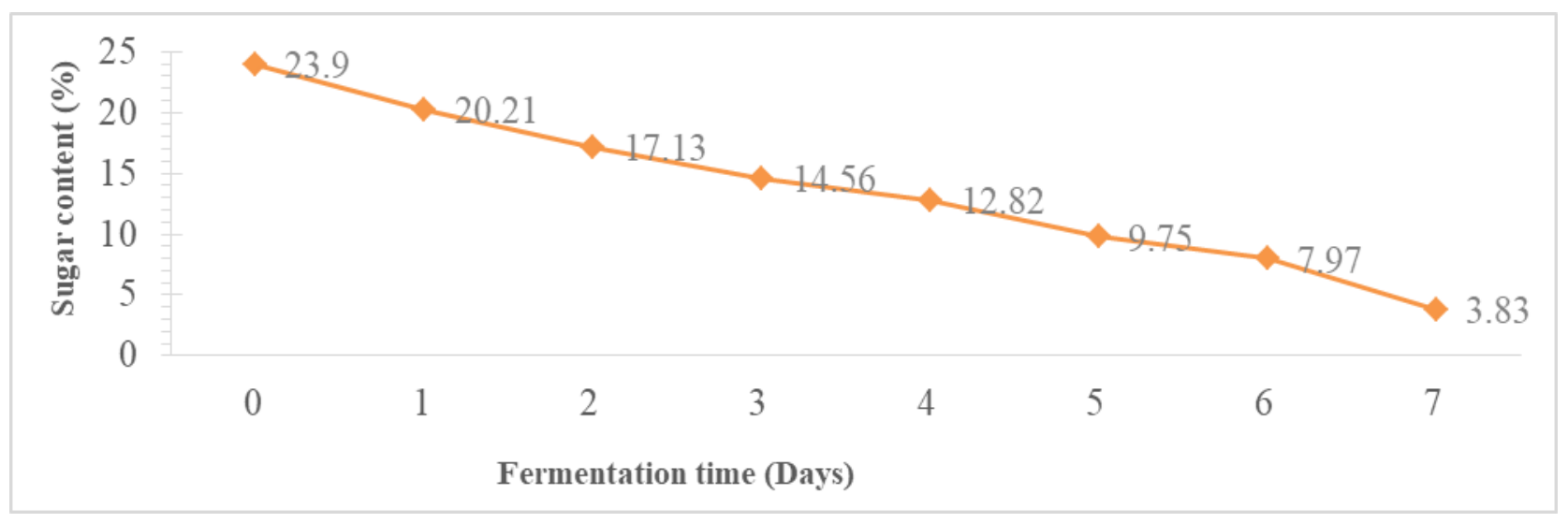

Figure 4 Changes in percentage sugar content during fermentation of the hydrolysate with Saccharomyces cerevisiae

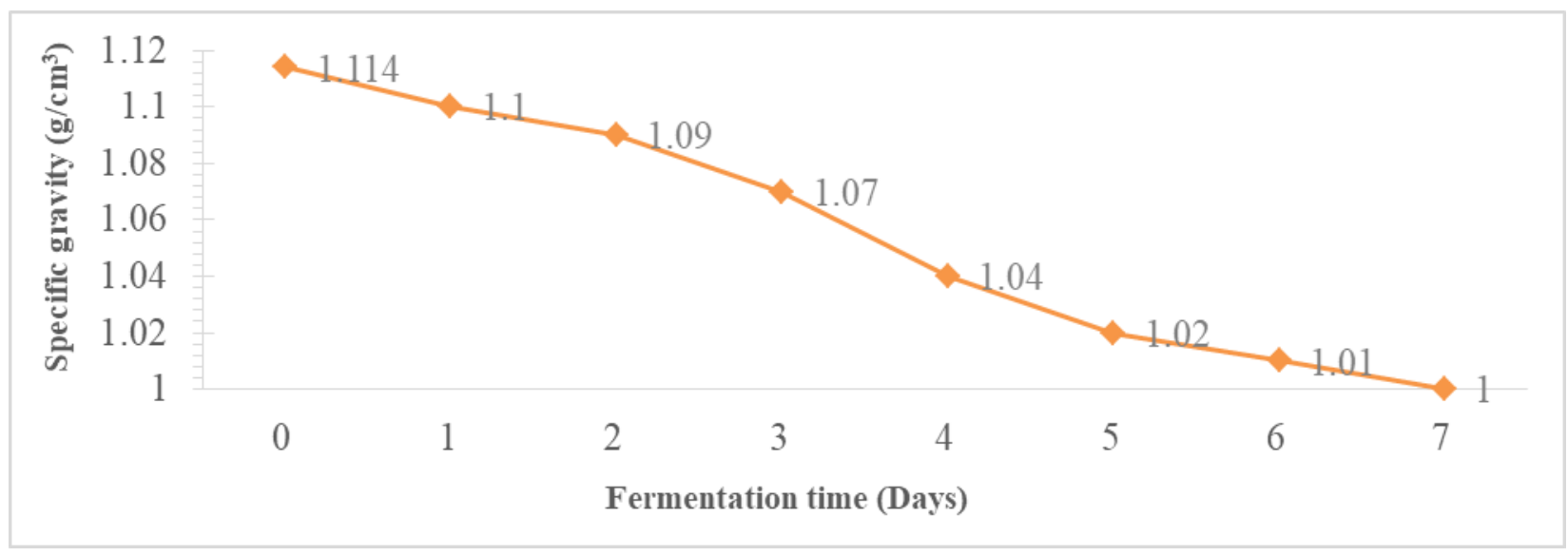

Figure 5 Changes in specific gravity $\left(\mathrm{g} / \mathrm{cm}^{3}\right)$ during fermentation of the hydrolysate with Saccharomyces cerevisiae

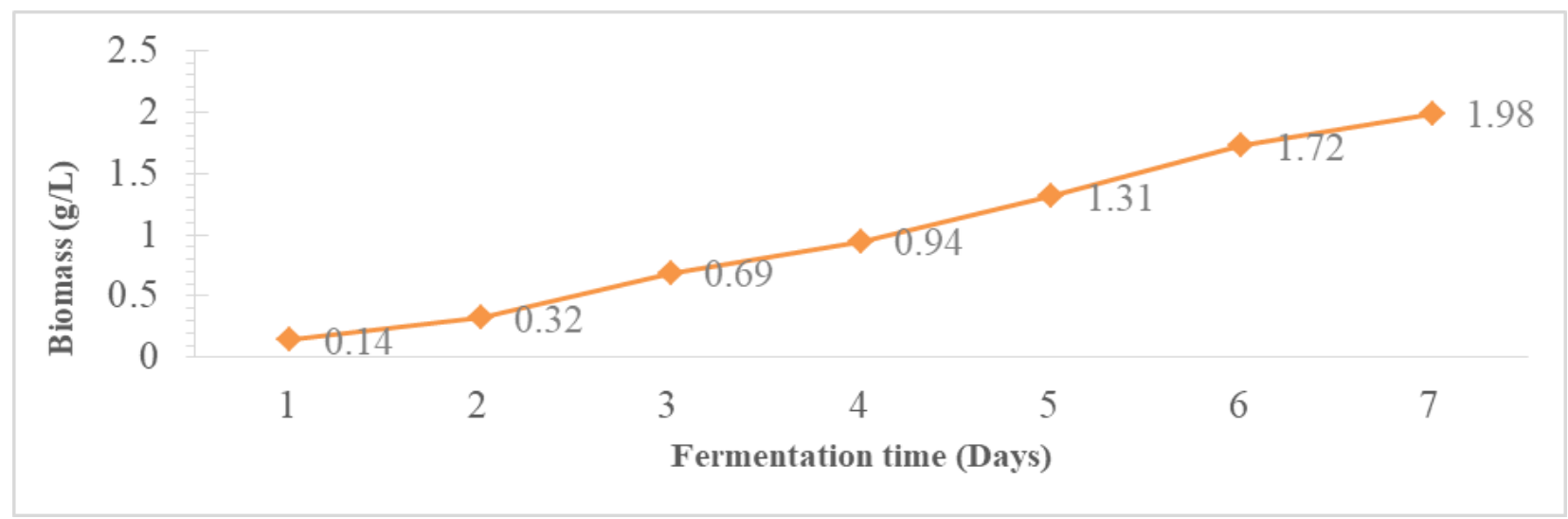

Figure 6 Biomass yield (g/L) during fermentation of the hydrolysate with Saccharomyces cerevisiae 


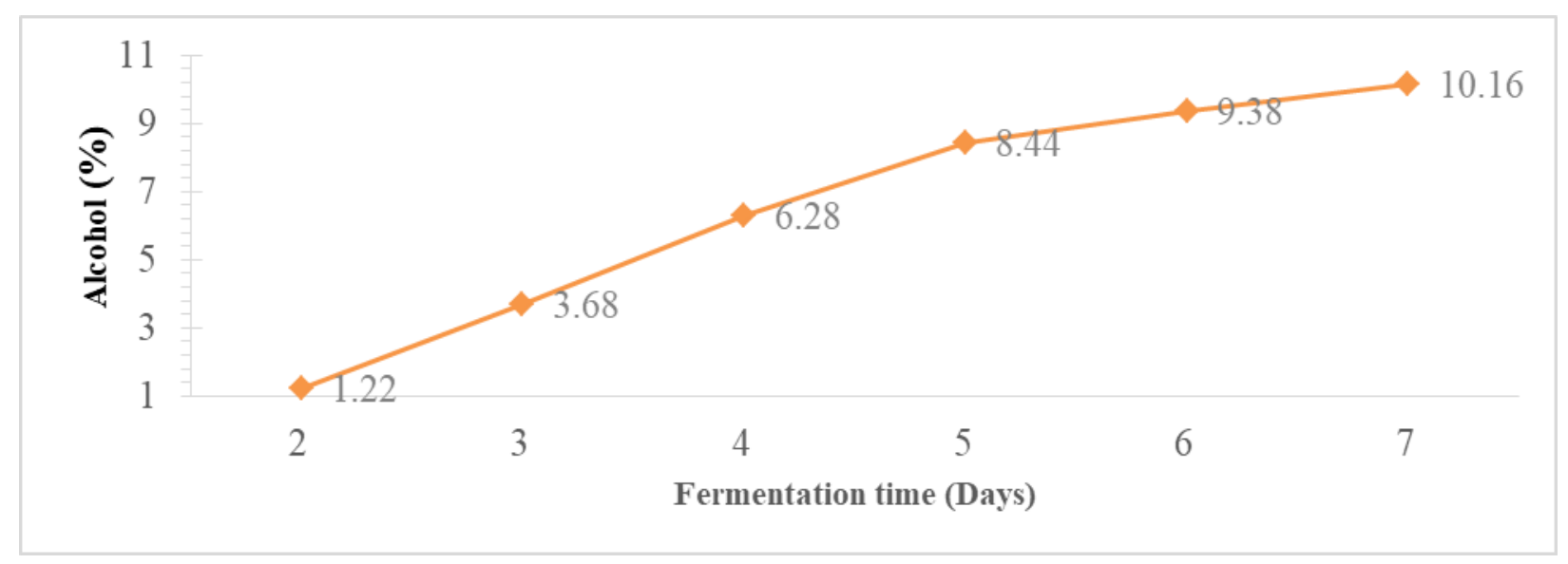

Figure 7 Quantity of alcohol produced during fermentation of the hydrolysate with Saccharomyces cerevisiae

Table 2 showed the quality characteristics of produced ethanol which includes average boiling point of $78.83 \pm 0.18{ }^{\circ} \mathrm{C}$ with a specific gravity of $0.90 \pm 0.07 \mathrm{~g} / \mathrm{cm}^{3}$. The biomass and alcohol yields were $1.98 \pm 0.21 \mathrm{~g} / \mathrm{L}$ and $10.16 \pm 0.12 \%(\mathrm{v} / \mathrm{v})$ respectively.

Table 2 Quality characteristics of produced ethanol

\begin{tabular}{lllll}
\hline Boiling point $\left({ }^{\circ} \mathrm{C}\right)$ & Specific gravity $\left(\mathbf{g} / \mathbf{c m}^{3}\right)$ & $\mathbf{p H}$ & Biomass (g/L) & Alcohol yield (\%) \\
\hline $78.83 \pm 0.18$ & $0.90 \pm 0.07$ & $6.07 \pm 0.45$ & $1.98 \pm 0.21$ & $10.16 \pm 0.12$ \\
\hline \multicolumn{5}{c}{ Values are given as mean \pm SD. }
\end{tabular}

\section{Discussion}

The wood particles and sawdust were hydrolysed using Trichoderma viride to activate saccharification. The hydrolysis of wood particles and sawdust yielded sugar content (\%) of $6.87 \pm 0.25$ and this indicted the production of cellulase as extracellular enzyme by Trichoderma [18]. This shows that optimization of the hydrolysate for effective production of alcohol by fermentation process became necessary as there are potentials in the increased utilization of the wood particles (waste) from wood processing. In [19], brix of up to $22 \%$ is required in the fermentation of substrates by yeasts. The $\mathrm{pH}$ of $6.20 \pm 0.15$ of the hydrolysate was slightly in the acidic range and this would discourage bacterial contaminants from interfering with the activity of the yeast.

During fermentation, changes were observed in the characteristics of the fermenting hydrolysate (Figures 1-7) in which the sugar content, $\mathrm{pH}$ and specific gravity reduced with fermentation time (days) while titratable acidity, alcohol yield and biomass increased with fermentation time (days). The decrease in $\mathrm{pH}$ was collaborated with the commensurate increase in the titratable acidity [20]. The produced carbondioxide $\left(\mathrm{CO}_{2}\right)$ combines with water to produce acid $\left(\mathrm{CO}_{2}+\right.$ $\mathrm{H}_{2} \mathrm{O} \rightarrow \mathrm{H}_{2} \mathrm{CO}_{3}$ ). This produced acid in the solution lowers the $\mathrm{pH}$ and increased the titratable acidity [20]. Palm wine yeasts are mainly of the Saccharomyces species and were reported to thrive well in high sugar conditions with good level of tolerance to alcohol [21]. This is the reason the production of acid during fermentation did not hinder the performance of the yeast, while temperature $\left({ }^{\circ} \mathrm{C}\right)$ of the fermenting medium fluctuated between $29 \pm 0.23$ and $30 \pm 0.11$. The fluctuation in temperature could be attributed to environmental factors that may affect fermentation [22].

The decrease in sugar content is due to consumption of sugar during fermentation which depletes the available quantity with time [20]. Alcohol production (\%) was recorded from the second day of fermentation (1.22 \pm 0.03$)$ and it increased to $10.16 \pm 0.12$ at the end of fermentation. The steady increase in the alcohol and biomass content with time was due to fermentation and metabolic activities of Saccharomyces cerevisiae [20] and this continual increase in biomass as was observed in this work is in line with the definition of fermentation by [23].

The produced ethanol when compared with standard was found to be at par with normal range (physical characteristics), with a boiling point of $78.83 \pm 0.18{ }^{\circ} \mathrm{C}$ and specific gravity of $0.98 \pm 0.07 \mathrm{~g} / \mathrm{cm}^{3}$. The alcohol (\%) yield of $10.16 \pm 0.12$, though low in content but was similar to the report of [22], could be attributed to differences in the choice of substrate used in the fermentation process. However, the residual sugar (\%) of $3.83 \pm 0.32$ may contribute to more ethanol and biomass yield if the fermentation time was extended. 


\section{Conclusion}

The results of this study have proved that Trichoderma viride is capable of producing an enzyme cellulase for hydrolysis of cellulosic materials such as sawdust. The production of $23.90 \pm 0.18 \%$ of sugar after optimization of the hydrolysate was commendable. Also, subsequent fermentation of the hydrolysate with palm wine yeast (Saccharomyces cerevisiae) produced both ethanol and biomass of considerable quantities. Therefore, it is evidently clear that wood particles and sawdust are potential substrates for production of ethanol and biomass; and should be harnessed. Hence, extending the fermentation time to exhaust the residual sugar could lead to higher ethanol yield considering the residual amount of sugar left after the seventh day.

\section{Compliance with ethical standards}

\section{Acknowledgments}

The authors are grateful to all contributors for their commitments. We are grateful to staff of Federal Institute of Industrial Research, Oshodi, Lagos State (FIIRO) for their assistance.

\section{Disclosure of conflict of interest}

No conflict of interest.

\section{References}

[1] Saxena RC, Adhikari DK and Goyal HB. (2009). Biomass-based energy fuel through biochemical routes: A review. Renewable Sustainable Energy, 13, 167-178.

[2] Otulugbu K. (2012). Production of ethanol from cellulose (sawdust), ARCADA,1 - 47.

[3] Nwakaire SL, Ezeoha BO and Ugwuishiwu SL. (2013). Production of cellulosic ethanol from wood sawdust. Agricultural Engineering International CIGR Journal, 15, 136-140.

[4] Reijnders L. (2006). Conditions for the sustainability of biomass based fuel use. Energy policy, 34, 863 -876.

[5] Nadeem M, Asghar U, Abbas S, Saif U and Syed Q. (2013). A potential tool to explore kallar grass (Leptochloafusca) as a substrate for bio-fuel production. Middle-East Journal of Science Resources, 18, 1133-1139.

[6] Lynd LR, Cushman JH, Nichols RJ and Wyman CE. (1991). Fuel ethanol from cellulosic biomass. Science, 251, 1318.

[7] Zhang J, Heiss C, Thorne PG, Bal C, Azadi P and Lynd LR. (2009).Formation of ethyl_xylopropyranoside during simultaneous saccharification and co_fermentation of paper sludge. Enzyme Microbiology Technology, 44, 196202.

[8] Das H and Singh SK. (2004). Useful byproducts from cellulosic wastes of agriculture and food industry - a critical appraisal. Critical Review Food Science Nutrition, 44 (2), 77 - 89.

[9] Mcaloon A, Taylor F, Yee W, Ibsen K and Wooley R. (2000). Determing the cost of producing ethanol from corn starch and lignocellulosicfeedstocks- Report No.NREL/TP580-28893. Eastern Regional Research Centre, Wyndmoor P.A and National Renewable Energy Laboratory.

[10] Yasuyuki M, Toyoki I, Yasuo TTH and Kazuhiko F. (2011). Conversion of sulfuric acid lignin generated during bioethanol production from lignocellulosic materials into polyesters with ecaprolactone. Journal of Wood Science, 57, $214-218$.

[11] Park I, Kim I, Kang K, Jihn H, Rhee I, Jin I and Jang H. (2010). Cellulose ethanol production from waste newsprint by simultaneous saccharification and fermentation using Saccharomyces cerevisiae KNU5377. Process Biochemistry, 45, $487-491$.

[12] Talebnia F, Karakashv D and Angelidaki I. (2010). Production of bioethanol from wheat straw: an overview on pretreatment, hydrolysis and fermentation. Bioresource Technology, 101(13), 4744 - 4753.

[13] James CS. (1995). Analytical Chemistry of Foods. Chapman and Hull, New York, 163 - 168.

[14] Sadler GD and Murphy PA. (2003). pH and Titrable Acidity. In: Food Analysis, 3, 120-126. 
[15] Oyeleke SB and Jibrin NM. (2009). Production of bioethanol from guinea corn husk and millet husk. African Journal of Microbiological Resources, 3(4), 147-152.

[16] Nwachukwu IN, Ibekwe VI, Nwabueze RN and Anyanwu BN. (2006). Characterization of palm wine yeast isolates for industrial utilization. African Journal of Biotechnology, 3(6), 1726 - 1733.

[17] Wang SN. (2011). Measurement of cell biomass concentration, Experiment No 9C.Biochemical Engineering Laboratory (ENCH 485).Department of Clinical and Biomolecular Engineering, University of Maryland, College Park, USA.

[18] Miettinen-Oinonen A and Suominen P. (2002). Enhanced production of Trichodermareeseiendoglucanases and use of the new cellulase preparations in producing the stone washed effect on denim fabric. Applied Environmental Microbiology, 68(8), 3656 - 3964.

[19] Onwuka GI. (2005). Food analysis and instrumentation, Theory and Practice.Naphthalein Prints, Lagos, 200.

[20] Ike CC, Onwuakor CE, Akwari DK and Nwokorie CC. (2019). Citric acid production by Aspergillusniger using banana and plantain peels. GSC Biological and Pharmaceutical Sciences, 8(2), 015-021.

[21] Jay MJ, Loessner MJ and Golden DA. (2005). Modern Food Microbiology, Seventh Edition. Springer Publishers, USA, 473-492.

[22] Mbajiuka CS, Ifediora AC, Onwuakor CE and Nwokoji LI. (2015). Fermentation of pods of cocoa (Theobroma cacao L) using palm wine yeasts for the production of alcohol and biomass. American Journal of Microbiological Research, 3(2), 80-84.

[23] Awan JA and Okaka JC. (1992). Elements of food spoilage and preservation. Institute of Management and Technology, 2, 123_205.

\section{How to cite this article}

Ike CC, Onwuakor CE, Akwari DK and Ogwuegbu HO. (2020). Bio-production of ethanol and biomass from wood particles and sawdust using conventional yeast. GSC Biological and Pharmaceutical Sciences, 11(1), 69-77. 